\title{
Gender Differences in Children's Psychological Well-Being in Mainland China: Risk and Protective Factors
}

\author{
Yanling Geng ${ }^{1} \cdot$ Longtao $\mathrm{He}^{2}$ (1)
}

Accepted: 9 September 2021 / Published online: 20 September 2021

(c) The Author(s) 2021

\begin{abstract}
Despite extensive research on children's psychological well-being, little consensus about gender's influence has been reached. In response, we examined gender differences in children's psychological well-being in mainland China, along with the gender-based risk and protective factors and their effects on psychological wellbeing. For a sample, we compiled data with 2466 children aged between 10 and 15 years old derived from the China Family Panel Studies. Among our results, an independent sample $t$ test indicated that girls in China reported higher psychological well-being than boys. A multiple regression analysis revealed that certain protective factors associated with children's competence and protective factors in their family and school systems could promote the psychological well-being of both boys and girls, while risk factors such as academic pressure and parent-child conflict were detrimental to the psychological health of all children regardless of gender. We discuss gender differences in those risk and protective effects, and with reference to our findings, we propose social service recommendations aimed at boosting the psychological well-being of children in mainland China.
\end{abstract}

Keywords Children in China · Psychological well-being · Gender · Risk factor · Protective factor

The term psychological well-being has been defined and operationalized in various ways (Adejumo, 2010). For one, scholars following the conventional mental health research tradition tend to use the term "psychological well-being" interchangeably with "mental health" to represent the absence of illness and dysfunction. In so doing, however, they have continued to raise the specter of negative connotations of

Longtao He

1zhlt01@hotmail.com

1 Department of Sociology and Social Work, Northwest University, Xi'an, People's Republic of China

2 Research Institute of Social Development, Southwestern University of Finance and Economics, 555 Liutai Avenue, Wenjiang District, Chengdu 611130, People's Republic of China 
psychological dysfunction and mental illness. For another, scholars influenced by the ideology of positive psychology have shifted the term's focus to positive psychological well-being and wellness (Hidalgo et al., 2010; Ryff \& Singer, 1996). Considering that both the positive and 'negative' aspects of psychological well-being matter a great deal to people, Warr (2012) suggested that a working definition of psychological well-being should cover both types of aspects. Along similar lines, Shek $(1999,2007)$ also advocated conceptualizing psychological well-being as the absence of pathological symptoms combined with the presence of positive attributes of mental health.

In mainland China, children's psychological well-being has recently attracted particular attention from social science researchers, some of whom have investigated gender differences in children's psychological well-being in empirical studies (Jones et al., 2016). However, consensus about whether boys or girls enjoy greater psychological well-being in mainland China has remained out of reach. For instance, some studies have shown that girls demonstrated greater psychological well-being than boys, who typically exhibited lower self-esteem, higher psychological distress, and greater rates of depression (Chen et al., 2009; Liu \& Zhao, 2016; Wong et al., 2009). However, other have revealed higher levels of psychological distress among girls than boys (Jiang, 2020), while still others have not shown any gender differences in children's psychological well-being in mainland China, given results that boys and girls exhibited similar levels of depression and satisfaction with their lives (Chen \& Chan, 2016; To et al., 2017). In part, the inconsistency of such findings can be attributed to the researchers' use of different non-representative regional data in their studies. To overcome such discrepancies, gender difference in children's psychological well-being should be examined with nationally representative data, especially in such a way as to explore the psychological well-being and the associated gender differences in a more comprehensive manner by incorporating both positive and negative definition of psychological well-being in a single research design.

Aside from gender-based differences in children's psychological well-being in mainland China, influencing factors of their psychological well-being also await exploration. From an ecological perspective, children's development and psychological well-being can be influenced by various factors at different ecological levels, with some playing protective roles (i.e., protective factors) and others being harmful (i.e., risk factors; Bronfenbrenner, 1992; Shek \& Siu, 2019). Among the various perspectives guiding the exploration of factors influencing children's psychological well-being, the positive youth development (PYD) approach, based on ecological theory, emphasizes that both internal developmental assets (e.g., children's psychosocial and academic competence) and external ones (e.g., influence of family and school) are important in promoting children's positive development and well-being (Qi et al., 2020; Shek et al., 2019). Along with the PYD approach, self-determination theory also suggests that children's well-being is directly associated with the satisfaction of their innate psychological needs for competence and relatedness (Deci \& Ryan, 2000), while expectancy-value theory proposes that relatively high parental expectations can enhance children's psychological development and wellbeing by promoting their motivation and self-assessment (Leung \& Shek, 2019). Added to those frameworks, social causation theory and the family stress model 
suggest that economic disadvantage may also affect children's development and well-being (Shek \& Ng, 2014). However, those perspectives, theories and models have been applied in theoretical and empirical investigations on the risk and protective factors of children's psychological well-being mostly in Western contexts, rarely in mainland China. Therefore, we are not sure whether the Chinese empirical evidence could fit with these theoretical frameworks. As suggested by Shek (2014) and Leung and Fung (2021), conducting such research in mainland China is important because it increases our knowledge about the quality of life among children in non-Western context. On top of that, gender differences in the ways that those factors affect children's psychological well-being in mainland China have also scarcely been explored.

Against those backgrounds, we sought to gauge gender differences in children's psychological well-being in mainland China in light of nationally representative data, as well as investigate potential risk and protective factors of their psychological well-being and whether those factors bear similar influence between boys versus girls. We expect that our findings can help to expand current understanding of children's psychological well-being and provide empirical evidence to guide the design and implementation of children's services in mainland China.

\section{Children's Competence and Psychological Well-Being}

According to the self-determination theory, competence refers to confidence and ability to perform well and deal with challenges (Ryan \& Deci, 2002). For children, competences in different domains, as internal developmental assets, are important for their positive development (Lerner et al., 2005; Shek et al., 2019). For school-age children who are developing intellectually, physically and socially, those domains refer to performing well in school, being physically healthy, and possessing good social skills. In empirical studies across cultures, achievement in those domains has been shown to relate significantly to children's higher psychological well-being (e.g., Borja et al., 2016; Garrido et al., 2013; Leung et al., 2021; Segrin \& Taylor, 2007; Shek \& Li, 2014).

\section{Influence of Family and School}

Three theories including the PYD approach, the self-determination theory, and the expectancy-value theory all emphasize the influence of family and school on children's psychological development. Both the PYD approach and the self-determination theory discuss the influence of family and school systems in satisfying children's need for relatedness, meaning children's feeling of being connected to or cared for by others and their sense of belonging in families, schools, and other ecosystems, with resources such as parent-child closeness, positive family communication, and caring school climate being important external assets in supporting their positive development (Deci \& Ryan, 2000; Shek et al., 2019). 
In the family system, children's relationships with their parents are important indicators of their sense of relatedness. Parent-child relationships have multiple dimensions, all with diverse influences. On the one hand, parent-child closeness and positive communication can make children feel loved and cared for, which can promote their development and well-being. On the other hand, parent-child conflict can damage children's sense of relatedness to their parents and their sense of belonging in the family, which may harm their psychological well-being and, in turn, prompt their involvement in risky behavior (Bradford et al., 2008; Lim et al., 2015; Low, 2021; Shek \& Ng, 2014). In the Chinese context in particular, another critical factor that requires attention is parent-child separation. Each year, millions of people living in rural China migrate to cities for work without their underage children, and the number of these 'left-behind children' with both parents migrating to cities has reached 697 million until 2018 (Ministry of Civil Affairs of the People's Republic of China, 2018). As empirical research has shown, parent-child separation is detrimental not only to children's sense of relatedness to their parents but also to their psychological development (Chen \& Chan, 2016).

In the school system, by comparison, children's sense of relatedness to their teachers and schools also influence their adjustment and psychological well-being (Van Ryzin et al., 2009). Children who have more satisfactory relationships with their teachers are more likely to feel cared for and supported, and children who are more content at school are also more likely to feel a higher sense of belonging, and both feelings arguably boost their psychological well-being and academic achievement (Chu et al., 2010; Suldo et al., 2013; Tam et al., 2020).

Unlike self-determination theory, which stresses how children's sense of competence and relatedness affects their psychological well-being, expectancy-value theory emphasizes the influence of parental expectations. According to expectancy-value theory, parental expectations can influence children's motivation for success and their self-assessment of competence, and, in turn, promote their psychological development (Leung \& Shek, 2019). The theory has been supported by empirical research in Hong Kong, in which children who reported higher parental expectations also reported higher cognitive competence and stronger self-identity (Leung \& Shek, 2019).

\section{Impact of Socioeconomic Status}

Social causation theory and the family stress model of economic hardship underscore the influence of the family's socioeconomic status on children's psychological well-being. According to social causation theory, lower socioeconomic status can precipitate adverse outcomes in psychological well-being (Dohrenwend \& Dohrenwend, 1969). Likewise, the family stress model of economic hardship suggests that financial strain on the family negatively influences children's psychological well-being due to the resulting increase in the emotional distress of the parent(s), the reduction in parent-child warmth, and the rise in parent-child conflict (Shek $\& \mathrm{Ng}, 2014)$. Ample empirical evidence supports the adverse effect of economic 
disadvantage on children's psychological development and well-being (Leung \& Shek, 2020; Shek, 2008). Li et al. (2019), for example, found that poverty in the family exerted a significant negative effect on children's positive psychological wellbeing and could likely contribute to mental illness. In other work, impoverished living conditions and residential crowding were associated with lower psychological well-being and increased difficulties in behavioral adjustment among children (Evans et al., 1998).

In sum, as the ecological model and its various theoretical applications have suggested, factors at different ecological levels have been found to correlate with children's psychological well-being. Among them, factors related to children's competence and relatedness, parental expectations, and family's socioeconomic status have attracted sustained attention from scholars, especially in Western contexts. However, since factors of children's psychological well-being in mainland China have not been as widely examined, it remains unclear how children's competence and relatedness, parental expectations, and family socioeconomic status jointly affect their psychological well-being and whether gender differences exist in the effects of those factors.

\section{Research Questions and Hypotheses of the Present Study}

To gauge gender differences in children's psychological well-being in mainland China, examine the related risk and protective factors, and investigate gender differences in their effects, we developed three research questions:

(1) In what ways does the psychological well-being of children in mainland China differ according to gender?

(2) What protective or risk-bearing influences do those factors (children's competence and relatedness, parental expectations, and family socioeconomic status) exert on the psychological well-being of children in mainland China?

(3) Do those risk and protective factors similarly affect the psychological well-being of boys and girls in mainland China?

Considering the inconsistency of empirical findings about the first question, we approached that question in an exploratory manner and proposed no hypothesis for it. For the second question, by contrast, we articulated three hypotheses:

Hypothesis 1 Guided by the PYD approach and self-determination theory, it was expected that factors able to enhance children's competence in schoolwork, physical health, and interpersonal interaction, as well as factors able to strengthen their sense of relatedness with family and school boost their psychological well-being, whereas factors such as academic stress and parent-child conflict that damage their sense of competence and relatedness lower it. 
Hypothesis 2 Based on expectancy-value theory, it was expected that higher parental expectations promote children's psychological well-being.

Hypothesis 3 According to the social causation theory and the family stress model of economic hardship, lower family socioeconomic status (i.e., lower income and impoverished living conditions) reduce children's psychological well-being.

Last, because current theoretical perspectives and empirical researches have not provided adequate reasons or evidence to support specific hypotheses regarding the third research question, we also approached that question as an exploratory one and proposed no hypothesis for it.

\section{Method}

\section{Data and Sample}

We used data from the China Family Panel Studies (CFPS 2014), a comprehensive national survey that collects information at individual, household, and community levels with multiple questionnaires. The sampling method consistently adopted by CFPS has been probability proportionate to size. In 2014, CFPS collected information from 37,147 adults, 8616 children, 13,946 households, and 621 communities in 25 provinces, municipalities, or autonomous regions in China. Of the children surveyed, only those aged between 10 and 15 years old had completed a self-report questionnaire addressing their psychological well-being. Thus, those 10- to 15-yearold children were selected as units of analysis for this study. After we excluded cases of children who had quit school or not registered in the Chinese government's household registration system, 2466 children remained in our final dataset for analysis. Data used in our study were collected with the CFPS Family Questionnaire, the CFPS Adult Proxy Report for a Child Questionnaire, and the CFPS Child SelfReport Questionnaire.

\section{Measures}

\section{Dependent Variables}

Adopting the conceptualization of psychological well-being as the presence of positive human functioning and mental attributes combined with the absence of psychological dysfunction (Shek, 2007; Stallings et al., 1997), we operationalized psychological well-being as the absence of psychological distress combined with the presence of happiness and confidence about the future.

In the CFPS, psychological distress was measured using the Kessler 6 Rating Scale, which contains six items: "How often in the past month did you feel so depressed / nervous / restless / fidgety / hopeless that nothing could cheer you up / that everything was an effort / that life was meaningless." The reverse-coded 
response categories range from 1 (never) to 5 (almost daily), with higher scores representing higher psychological distress. Cronbach's alpha of the recoded Kessler 6 Rating Scale was 0.795, and the mean of its six items was used to represent psychological distress as a dependent variable.

Happiness was measured with a single question (i.e., "Are you happy?"), as was confidence about the future (i.e., "Are you confident about your future?"), both in response categories ranging from 0 (Not at all) to 10 (Very much), with higher scores representing greater happiness and greater confidence about the future.

\section{Independent Variables}

Independent variables were organized into several categories, including children's competence and relatedness, parental expectations, and family's socioeconomic status.

For children's competence, we included responses about physical health and frequency of physical exercise, academic performance and academic pressure, and interpersonal popularity and interpersonal skills. First, health was measured by responses to one question (i.e., "How would you rate your health status?"), and the reverse-coded answer categories ranging from 1 (poor) to 5 (excellent). Second, weekly physical exercise frequency was measured with the question "Including physical education, how often did you participate in physical exercise in the past week?" Third, academic performance was measured with two questions (i.e., "What was the child's average grade in Chinese language or grammar last semester?" and "What was the child's average grade in math last semester?"), with response categories ranging from 1 (excellent) to 4 (poor) that we reverse-coded. In turn, the mean of children's Chinese and math scores was used to represent their overall academic competence. Fourth, academic pressure was measured by responses to one question (i.e., "How much academic pressure do you put on yourself?"), with answers ranging from 1 (no pressure) to 5 (a lot of pressure). Last, respondents' interpersonal popularity and interpersonal skills were measured with two questions (i.e., "Do you think you are popular?" and "Is it easy for you to get along well with others?"), both with answer categories ranging from 0 (not at all) to 10 (very much).

Next, factors of parent-child relationship and children's satisfaction with their teachers and schools were included in the category of children's relatedness. For parent-child relationship, the factors included experience of parent-child separation, parent-child closeness, frequency of high-quality parent-child communication, and frequency of parent-child conflict. In the CFPS, parent-child separation was measured with one question (i.e., "How long did the child live with his or her father or mother in the past year?"), with reverse-coded response categories ranging from 1 (almost never) to 7 (almost the entire year), in which higher scores indicated a longer period of living together and, by the same token, a shorter period of separation. Parent-child closeness was measured with another question (i.e., "Do your parents know whom you are with when you are not at home?"), with recoded answer categories ranging from 1 (never know) to 5 (always know). By contrast, frequency of high-quality parent-child communication and parent-child conflict were measured by asking two questions (i.e. "In the past month, how many times did you and your parents have a heart-to-heart talk?" and "In the past month, how many times 
did you quarrel with your parents?"). Last, for children's relatedness with teachers and their schools, children also answered two questions (i.e., "Are you satisfied with your school?" and "Are you satisfied with your head teacher?"), both with answer categories ranging from 1 (extremely unsatisfied) to 5 (extremely satisfied).

As for parental expectations and family's socioeconomic status, we included parental educational expectations, annual household income, and family living conditions in analysis. In particular, parents' educational expectations were measured by asking the child's primary caregiver one question (i.e., "What is the highest level of education that you wish your child could obtain?"), with recoded response categories ranging from 0 (no need to go to school) to 8 (doctoral degree). Next, annual household income was measured with another question (i.e., "In the past 12 months, what was your family's total income?"). Last, living conditions were measured based on the interviewers' rating of "Neatness of the respondent's home" and "Crowdedness in the respondent's home", both with response categories ranging from 1 (very messy / crowded) to 7 (very clean / uncrowded).

\section{Data Analysis}

Data analysis was conducted with the Statistical Package for Social Science. The status quo of respondents' psychological well-being was assessed in a descriptive analysis, whereas gender differences in those indicators were gauged using an independent sample $t$ test. Because multiple regression is generally used to probe the relationship between multiple predictor variables and one dependent variable, we performed multiple regression according to gender as a way to investigate the possible protective and risk-bearing effects of independent factors on respondents' psychological well-being. The model estimation can be explained with the following equation:

$$
\text { PWB }=b_{1} x_{1}+b_{2} x_{2}+\cdots+b_{n} x_{n}+c
$$

in which $P W B$ represents psychological well-being, $x_{\mathrm{i}}(i=1,2 \ldots n)$ are the independent variables, and $b_{\mathrm{i}}(i=1,2 \ldots n)$ are the estimated coefficients. Last, the $t$ test was used to verify whether gender had a statistically significant effect on each independent variable's impact on children's psychological well-being in China.

\section{Results}

\section{Descriptive Statistics and Bivariate Correlations}

According to the results of our descriptive analysis (see Table 1), girls in our sample reported lower psychological distress $(M=1.494, S D=0.573)$ than boys $(M=1.535$, $S D=0.593)$, greater happiness $(M=8.440, S D=1.829)$ than boys $(M=8.090$, $S D=1.976)$, and higher confidence about the future $(M=7.900, S D=1.880)$ than boys $(M=7.820, S D=1.902)$. Those results support the findings of Chen et al. 


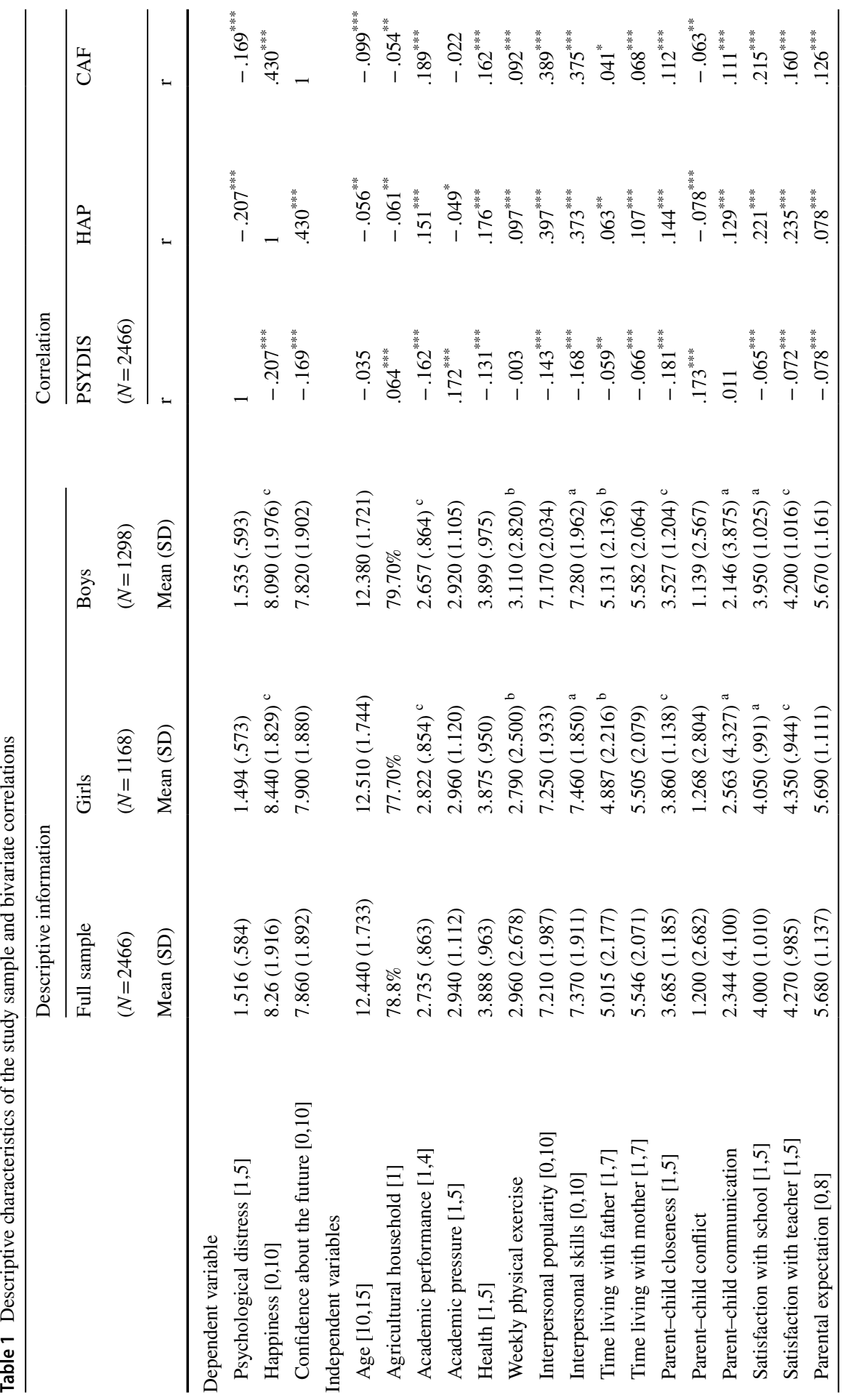




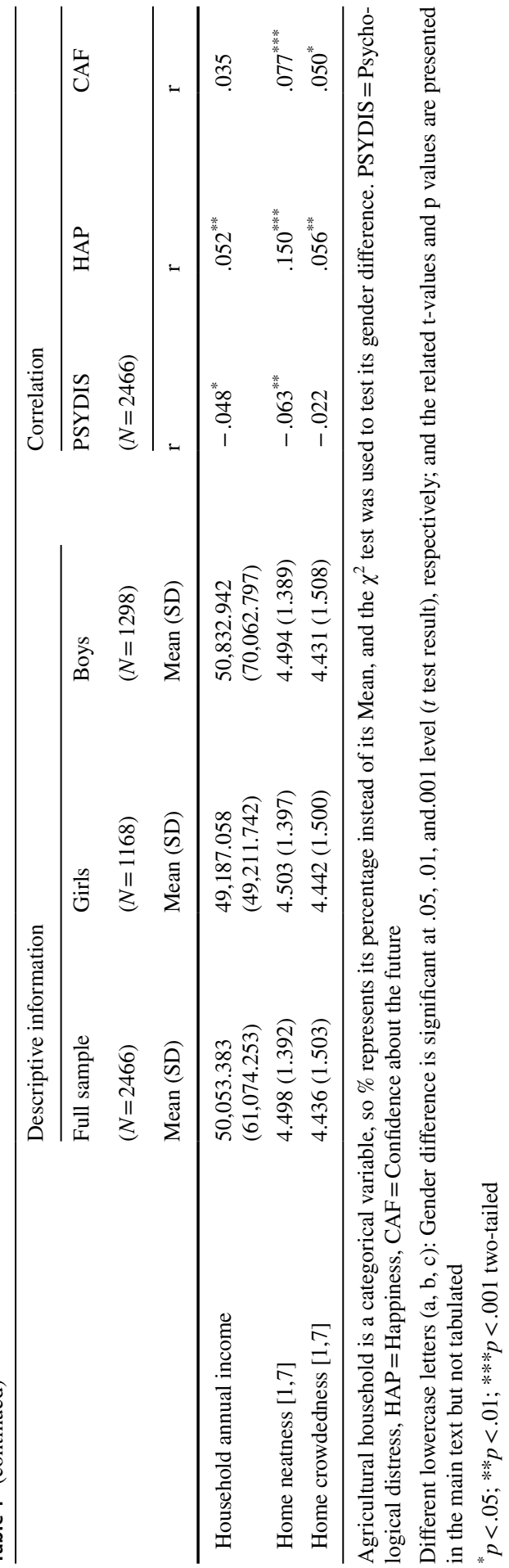


(2018) and Wang and Zhou (2017) that girls in China enjoy higher psychological well-being than boys. However, gender difference for those indicators in our study was only statistically significant for happiness, $t(2462)=4.536, p=0.000$ (not tabulated).

In addition to disparities in psychological well-being, significant gender differences in multiple predictor variables emerged between girls and boys. For example, regarding children's competence, girls reported better academic performance $(M=2.822, S D=0.854)$ than boys $(M=2.657, S D=0.864), \quad t(2464)=4.777$, $p=0.000$ (not tabulated) and better interpersonal skills $(M=7.460, S D=1.850)$ than boys $(M=7.280, S D=1.962), t(2458)=2.421, p=0.016$ (not tabulated).

In terms of children's relatedness with parents, boys lived with their fathers for longer $(M=5.131, S D=2.136)$ than did girls $(M=4.887, S D=2.216)$, $t(2415)=-2.777, p=0.006$ (not tabulated). Girls reported more frequent high-quality communication with their parents $(M=2.563, S D=4.327)$ than boys $(M=2.146$, $S D=3.875), t(2355)=2.513, p=0.012$ (not tabulated) and kept closer connections with them $(M=3.860, S D=1.138)$ than boys did $(M=3.527, S D=1.204)$, $t(2458)=7.052, p=0.000$ (not tabulated).

Regarding children's relatedness with teachers and schools, girls reported higher satisfaction with school $(M=4.050, S D=0.991)$ than boys $(M=3.950, S D=1.025)$, $t(2464)=2.468, p=0.014$ (not tabulated) and greater satisfaction with teachers $(M=4.350, S D=0.944)$ than boys $(M=4.200, S D=1.016), t(2464)=3.686$, $p=0.000$ (not tabulated).

Bivariate correlation analysis showed that all of the independent variables were significantly correlated with several, if not all, of the dependent indicators. Thus, all independent variables were included in the subsequent regression analysis.

\section{Multiple Regression Analysis}

The results of the multiple regression analysis appear in Table 2. Overall, the predictor variables explained $13.1 \%$ and $16.0 \%$ of the variance in girls' and boys' psychological distress, $23.2 \%$ and $30.6 \%$ of the variance in girls' and boys' happiness, and $25.7 \%$ and $24.7 \%$ of the variance in girls' and boys' confidence about the future, all respectively.

In relation to psychological distress, many of children's competence-related factors were influential, albeit to varying degrees. For example, better academic performance reduced the psychological distress of both girls $(\beta=-0.064, p<0.05)$ and boys $(\beta=-0.127, p<0.001)$, as did better interpersonal skills $(\beta=-0.102, p<0.01$ for girls; $\beta=-0.094, p<0.01$ for boys). Better physical health, by contrast, lowered psychological distress among boys $(\beta=-0.094, p<0.001)$ but not girls. On the contrary, higher academic pressure, the factor liable to damage children's sense of competence, increased both girls' $(\beta=0.112, p<0.001)$ and boys' $(\beta=0.215, p<0.001)$ psychological distress, although significantly more among boys, $t(2464)=2.898$, $p=0.004$ (not tabulated).

As for the effects of competence-related factors on children's happiness and confidence about the future, physical exercise promoted girls' happiness $(\beta=0.065$, $p<0.05)$ and confidence about the future $(\beta=0.056, p<0.05)$, and its effect on happiness differed significantly between girls and boys, $t(2464)=1.997, p=0.046$ (not 
Table 2 Multiple Regression Results for children's psychological well-being by gender

\begin{tabular}{|c|c|c|c|c|c|c|}
\hline & \multicolumn{2}{|c|}{ Psychological distress } & \multicolumn{2}{|c|}{ Happiness } & \multicolumn{2}{|c|}{$\begin{array}{l}\text { Confidence about the } \\
\text { future }\end{array}$} \\
\hline & Girls & Boys & Girls & Boys & Girls & Boys \\
\hline & $\beta$ & $\beta$ & $\beta$ & $\beta$ & $\beta$ & $\beta$ \\
\hline Age & -.037 & $-.081^{* *}$ & $-.054^{*}$ & .014 & $-.088^{* * *}$ & -.047 \\
\hline Agricultural household & -.009 & .03 & -.01 & $.055^{*}$ & .014 & .009 \\
\hline \multicolumn{7}{|l|}{ Competence } \\
\hline Health & -.043 & $-.094^{* * *}$ & $.070^{* *}$ & $.070^{* *}$ & $.072^{* *}$ & $.055^{*}$ \\
\hline Weekly physical exercise & .021 & .044 & $.065^{*} \mathrm{a}$ & $-.005 \mathrm{a}$ & $.056^{*}$ & .001 \\
\hline Academic performance & $-.064^{*}$ & $-.127^{* * * *}$ & .043 & .024 & $.078^{* *}$ & $.094^{* * *}$ \\
\hline Academic pressure & $.112^{* * *} \mathrm{~b}$ & $.215^{* * *} \mathrm{~b}$ & -.023 & -.027 & .016 & -.001 \\
\hline Interpersonal popularity & -.047 & -.04 & $.228^{* * *}$ & $.250^{* * * *}$ & $.262^{* * * *}$ & $.198^{* * *}$ \\
\hline Interpersonal skills & $-.102^{* *}$ & $-.094^{* *}$ & $.200^{* * *}$ & $.170^{* * *}$ & $.191^{* * *}$ & $.213^{* * *}$ \\
\hline \multicolumn{7}{|l|}{ Relatedness } \\
\hline Time living with father & .008 & $-.066^{*}$ & -.014 & .005 & .008 & -.02 \\
\hline Time living with mother & -.047 & .005 & .037 & $.074^{*}$ & .000 & .042 \\
\hline $\mathrm{P}-\mathrm{C}$ closeness & $-.147^{* * *}$ & $-.103^{* * * *}$ & .023 & $.063^{* *}$ & .011 & .026 \\
\hline $\mathrm{P}-\mathrm{C}$ conflict & $.166^{* * *}$ & $.129^{* * *}$ & -.046 & $-.078^{* * *}$ & -.036 & $-.055^{*}$ \\
\hline $\mathrm{P}-\mathrm{C}$ communication & .035 & .039 & $.065^{*}$ & $.076^{* *}$ & $.053^{*}$ & $.054^{*}$ \\
\hline Satisfaction with school & $-.074^{*} \mathrm{~b}$ & $.044 \mathrm{~b}$ & .042 & $.080^{* *}$ & $.047 \mathrm{a}$ & $.135^{* * *} \mathrm{a}$ \\
\hline Satisfaction with teacher & -.021 & -.055 & $.121^{* * * *}$ & $.158^{* * *}$ & $.084^{* *}$ & .019 \\
\hline \multicolumn{7}{|l|}{ Parental expectation } \\
\hline Parental expectation & -.034 & -.009 & -.013 & .039 & $.056^{*}$ & $.067^{* *}$ \\
\hline \multicolumn{7}{|l|}{ Socioeconomic status } \\
\hline Household income & -.028 & -.02 & .022 & -.001 & -.006 & -.007 \\
\hline Home neatness & -.008 & -.034 & $.072^{*} \mathrm{a}$ & $.145^{* * *} \mathrm{a}$ & .002 & .036 \\
\hline Home crowdedness & .052 & -.001 & -.047 & -.031 & -.013 & .013 \\
\hline $\mathrm{R}^{2}$ & .131 & .16 & .232 & .306 & .257 & .247 \\
\hline
\end{tabular}

Different lowercase letters (a, b): Gender difference is significant at .05 and .01 level ( $t$ test result), respectively; and the related t-values and p values are presented in the main text but not tabulated ${ }^{*} p<.05 ; * * p<.01 ; * * * p<.001$ two-tailed

tabulated). Better academic performance related to greater confidence about the future for both girls $(\beta=0.078, p<0.01)$ and boys $(\beta=0.094, p<0.001)$. Beyond that, better health ( $\beta$ range from 0.055 to 0.072 ), higher interpersonal popularity ( $\beta$ range from 0.198 to 0.262 ), and better interpersonal skills ( $\beta$ range from 0.170 to 0.213 ) all significantly promoted girls' and boys' happiness and confidence about the future.

Concerning children's relatedness with parents, living with one's father for longer reduced boys' psychological distress $(\beta=-0.066, p<0.05)$, while living with one's mother increased boys' happiness $(\beta=0.074, p<0.05)$. Meanwhile, parent-child closeness lowered the psychological distress of both girls $(\beta=-0.147, p<0.001)$ 
and boys $(\beta=-0.103, p<0.001)$ and promoted happiness among boys $(\beta=0.063$, $p<0.01)$. High-quality parent-child communication increased the happiness of both girls $(\beta=0.065, p<0.05)$ and boys $(\beta=0.076, p<0.01)$, along with their confidence about the future (girls: $\beta=0.053, p<0.05$; boys: $\beta=0.054, p<0.05$ ). Parent-child conflict, on the contrary, increased the psychological distress of both girls $(\beta=0.166, p<0.001)$ and boys $(\beta=0.129, p<0.001)$ as well as reduced boys' happiness $(\beta=-0.078, p<0.001)$ and confidence about the future $(\beta=-0.055, p<0.05)$.

In terms of children's relatedness with teachers and schools, satisfaction with teachers exerted no significant influence on children's psychological distress, although it did promote the happiness of both girls $(\beta=0.121, p<0.001)$ and boys ( $\beta=0.158, p<0.001)$, along with girls' confidence about the future $(\beta=0.084$, $p<0.01)$. Satisfaction with school reduced girls' psychological distress $(\beta=-0.074$, $p<0.05)$ and boosted boys' happiness $(\beta=0.08, p<0.01)$ and confidence about the future $(\beta=0.135, p<0.001)$. As a contrast, the influence of children's satisfaction with school on reducing psychological distress was significantly higher among girls, $t(2464)=2.749, p=0.006$ (not tabulated), and its effect on promoting the confidence about the future was significantly greater among boys, $t(2464)=2.146, p=0.032$ (not tabulated).

As for the influence of parental expectations and the family's socioeconomic status, parental educational expectations did not significantly influence children's psychological distress or happiness, although it did enhance their confidence about the future (girls: $\beta=0.056, p<0.05$; boys: $\beta=0.067, p<0.01$ ). Neatness of one's home helped to boost girls' $(\beta=0.072, p<0.05)$ and boys' $(\beta=0.145, p<0.001)$ happiness, whereas the influence of annual household income and the crowdedness of the home on children's psychological well-being was not significant. By gender, the influence of neatness of one's home on happiness was significantly higher among boys than girls, $t(2464)=2.007, p=0.045$ (not tabulated).

\section{Discussion}

In our study, we examined the psychological well-being of children in mainland China, its protective and risk factors, and the gender differences related to them. Guided by ecological systems theory and the PYD approach, as well as combining self-determination theory, expectancy-value theory, and social causation theory for a theoretical rationale, we hypothesized that factors related to children's competence and relatedness, parental expectations, and the family's socioeconomic status would significantly influence the psychological well-being of children in mainland China.

\section{Gender Differences in Children's Psychological Well-Being}

Our findings showed that boys in mainland China reported lower psychological wellbeing than girls, whose well-being manifested as less psychological distress, greater happiness, and higher confidence about the future. However, gender differences in 
psychological well-being were statistically significant for happiness only, not for psychological distress or confidence about the future.

As for the possible reasons, the literature shows that girls generally outperform boys in academic achievement and interpersonal relationship during elementary and middle school (Zhao, 2000), and the same dynamic was indeed the case for the girls in our sample. Meanwhile, girls in China are less pressured to achieve personal success (Shek \& Liu, 2014). Taken together, it is highly possible that the better academic performance, the better interpersonal relationship, and the lower achievement pressure benefits girls in mainland China and contributes to their being significantly happier than boys.

However, Shek and Wu (2014) cautioned that even though girls in mainland China are less pressured than boys to pursue personal success, they are expected to be empathetic, caring, and sensitive on an interpersonal level. This gender role expectation increases girls' sensitive to people's evaluation feedback, thus heightening girls' internal distress and negative self-evaluation beyond those of boys (Pomerantz et al., 2002). This gender role difference might reduce the influence of girls' advantage in schoolwork and interpersonal relationship, and narrow down the gender differences in boys' and girls' psychological distress and confidence about the future.

\section{Gender Differences in Protective and Risk Factors of Children's Psychological Well-Being}

Supporting Hypothesis 1, competence-related factors of children in China, including their physical health, academic performance, interpersonal popularity and skills, had protective effects on the psychological well-being of both girls and boys, for whom academic pressure was a shared risk factor.

Among the protective effects of the competence-related factors, effects of interpersonal popularity and skills ranked the highest, followed by academic performance and physical health. Even though gender differences in the effects of those factors on psychological well-being were not significant, girls reported significantly better academic performance and interpersonal skills than boys, which helped to consolidate girls' leading position in reporting higher overall psychological wellbeing than boys.

Worldwide, girls commonly outperform boys in academic assessments and interpersonal interactions. Reviewing the literature, we identified several proposed explanations for those gender differences. For example, in terms of the gender difference in interpersonal skills, the difference in gender socialization has been proposed as contributing factor. In particular, whereas boys are encouraged to uphold traditional expectations of men, including competitiveness and aggressiveness, girls are encouraged to act in more prosocial ways by being kind, patient, and accommodating, which helps them to become more sociable in general (Umberson et al., 1996). Similar to the global trend, the phenomenon is also common in China and may help to explain why girls in our sample reported higher interpersonal skills than boys. 
In terms of academic performance, at least three possible reasons explain why girls outperform boys. First, compared with boys, girls are expected to be interpersonally sensitive and concerned with pleasing authority figures such as parents and teachers, which may urge them to intensify their efforts to perform well in school (Pomerantz et al., 2001). Second, unlike boys, who usually adopt self-confident perceptions about their abilities, girls are more apt to view academic performance as a manifestation of their capability and thus to exert more effort to excel in their studies and on academic assessments (Roberts, 1991). Third, according to one study conducted in China, girls have stronger academic consciousness and better study habits than boys, which may further widen the gender gap in academic performance (Zhao, 2000).

As for the effect of academic pressure, no significant gender difference in the perceived level of academic pressure surfaced among our respondents, although the influence of academic pressure on psychological distress was greater among boys than girls. Generally, boys are expected to show a higher level of confidence and possess a higher level of self-efficacy than girls (Catalano et al., 2004). Thus, because boys and girls in our sample reported a similar level of pressure, it is highly likely that the internal pressure shouldered by boys was greater than that shouldered by girls, which may have aggravated boys' psychological distress to a greater degree.

Further supporting Hypothesis 1, our findings demonstrated that factors associated with children's relatedness-parent-child closeness, high-quality parent-child communication, and satisfaction with schools and teachers-were protective factors for children's psychological well-being in China. However, parent-child conflict was a risk factor, for it increased psychological distress among boys and girls as well as decreased boys' happiness and confidence about the future.

Among the protective factors associated with relatedness in family, parent-child closeness decreased the psychological distress of our respondents, while high-quality parent-child communication promoted their happiness and confidence about the future. Although gender differences in the effects of those two variables on children's psychological well-being were not significant, girls did report significantly higher parent-child closeness and more frequent high-quality parent-child communication than boys, and that difference could partly explain why girls in our sample reported higher psychological well-being than boys. In the Chinese culture, daughters are often compared to a parent's "warm, close-fitting jacket" ("tiē shēn xiăo mián ăo"), which suggests the close, warm relationship expected between parents and daughters. Therefore, it is unsurprising that girls reported significantly higher closeness and more frequent high-quality communication with their parents than boys in our study.

Regarding the influence of the school system, girls again reported significantly higher satisfaction than boys with their schools and teachers, which corroborates published empirical evidence and helped to boost girls' psychological well-being. From an empirical standpoint, gender has been reported as a strong predictor for satisfaction with schools and teachers (Saleh et al., 2019). Girls, educated to be prosocial and equipped with better skills than boys in managing interpersonal relationships, tend to be more able to maintain satisfactory relationships with their teachers. By extension, influenced by their better relationship with teachers and classmates 
as well as their better academic performance than boys, they are also more likely to enjoy higher satisfaction with their schools (Hui \& Sun, 2010).

Supporting Hypothesis 2, our findings revealed that higher parental educational expectations benefited children's psychological well-being in mainland China by promoting both girls' and boys' confidence about the future, as consistent with the assumptions of expectancy-value theory (Leung \& Shek, 2019). As for Hypothesis 3 , neither household income nor crowdedness at home significantly related to the psychological well-being of children in mainland China. Thus, the hypothesis 3 was partly rejected.

Related with hypothesis 3, some research conducted in mainland China and Hong Kong reported that there is a statistically significant association between economic disadvantage and children's psychological development (See Li et al., 2019; Shek, 2008). However, in this study, no significant influence of household income on respondents' psychological well-being is shown. We speculate that the reason for such divergence lies in the ways how economic status is operationalized as variables. Economic status categorized as economic disadvantaged / non-disadvantaged is a categorical variable in previous studies mentioned above, and such variable was used for representing a state of absolute poverty. While in our study, we utilized a continuous variable - that is, household income - as our indicator for the financial factor in relation to children's psychological development. Thus, in terms of the influence of socioeconomic status, the difference between current study and previous researches suggests that absolute poverty conditions have adverse effects on children's psychological well-being rather than the relatively continuous difference in household income. Likewise, supporting our speculation, two research conducted in Hong Kong by Fung (2021) and Low (2021) also reported that household income in their studies had no significant influence on children's psychological wellbeing in terms of anxiety/depression, aggressive/delinquent behavior, and suicidal ideation.

Among the variables related to family's socioeconomic status, the neatness of one's home was the sole factor with significant influence on children's psychological well-being. However, home neatness was also influenced by the attitude and living habit of adults in the family, in addition to the influence of the family's socioeconomic status. And because parents who are more capable of maintaining order at home may also be better prepared to provide children with timely support, it is quite possible that the attitude and living habit of parents matter more than the family's socioeconomic status (Saxbe \& Repetti, 2010).

By and large, concerning the protective and risk factors associated with children's psychological well-being in mainland China, our findings support self-determination theory and expectancy-value theory, which suggest that children's competence and relatedness, and parental expectations are important factors of children's psychological development and well-being. However, our study did not reveal strong empirical evidence in support of social causation theory, because the effects of neither annual household income nor crowdedness at home were significant. Beyond that, by relating gender differences in children's psychological well-being in mainland China with gender differences in their risk and protective factors, we found that boys' lower psychological well-being might be partly explained by their relatively 
lower scores in protective factors (e.g., academic and interpersonal achievement and relatedness with family and school) and their relatively higher sensitivity to the harmful effects of risk factors such as academic pressure.

\section{Limitations and Implications}

Our study involved several limitations. First, due to a gap in the data from the CFPS survey, we could not examine how children's relatedness with peers influenced their psychological well-being. Similar to their relatedness with parents and teachers, children's relatedness with peers is also considered to be important for their psychological development (Pascuzzo et al., 2013). However, because the 2014 CFPS survey did not collect much information on peer relationship, it was impossible to explore its specific influence in our study. Second, considering the regional heterogeneity of mainland China, it would be helpful to include regional and/or municipal variables in analyses such as ours in order to correct any possible bias stemming from clustering. However, because neither regional nor municipal information was collected by the CFPS, we also could not control for the influence of regional heterogeneity in our study. Third, because we adopted a cross-sectional research design and used a single wave of CFPS data in analysis, we struggled to make accurate causal inferences about the relationships between independent variables and children's psychological well-being. All of those limitations highlight avenues for future research on or related to our topic.

Despite those limitations, our study does advance current understandings of children's psychological well-being in China, including its status quo, its protective and risk factors, and gender differences therein. Those findings also stand to support the design and implementation of evidence-based social services for children in mainland China.

First, using large-scale national data, our study revealed that boys in mainland China reported lower psychological well-being than girls, which sheds light on the importance of caring for and promoting the psychological well-being of boys. Second, supporting the PYD approach, self-determination theory, and expectancy-value theory, protective factors related to children's personal competence-that is, internal developmental assets (e.g., better health, better academic performance, and better interpersonal relationships and skills) - and protective factors in family and school systems - that is, external developmental assets (e.g., closer relationship with parents, more frequent high-quality communication with parents, higher parental expectations, and satisfactory relationship with schools and teachers)-promoted the psychological well-being of both boys and girls in mainland China. In turn, that finding reveals the importance of providing comprehensive asset-building services to children as a means to promote their positive development and psychological well-being. And useful practical suggestions related to asset-building and PYD can be found in the publications of Shek and colleagues based on their recent intervention studies in Hong Kong and mainland China (Ma et al., 2019; Shek \& Zhu, 2020; Zhu \& Shek, 2020). Third, as our analysis revealed, other than reporting lower psychological well-being than girls, boys also reported significantly lower 
academic achievement, worse interpersonal skills, lower parent-child closeness, less frequent high-quality communication with parents, and lower satisfaction with their schools and teachers than girls did, all of which are important protective factors for children's psychological well-being. Thus, it is necessary for social workers and psychology professionals to note those differences and design more boy-friendly service projects in domains that promote academic support, interpersonal skills, parent-child communication, and school-based social work.

Funding This research was funded by Shaanxi Provincial Social Science Foundation of China (Project No.:2021F010) and the Youth Project of Humanities and Social Sciences (Project No.: 20XJC840001) of the MOE (Ministry of Education in China). The funders have no role in the protocol design, the writing of the protocol, or the decision to submit the protocol.

\section{Declarations}

Conflict of interest We have no known conflict of interest to disclose.

Open Access This article is licensed under a Creative Commons Attribution 4.0 International License, which permits use, sharing, adaptation, distribution and reproduction in any medium or format, as long as you give appropriate credit to the original author(s) and the source, provide a link to the Creative Commons licence, and indicate if changes were made. The images or other third party material in this article are included in the article's Creative Commons licence, unless indicated otherwise in a credit line to the material. If material is not included in the article's Creative Commons licence and your intended use is not permitted by statutory regulation or exceeds the permitted use, you will need to obtain permission directly from the copyright holder. To view a copy of this licence, visit http://creativecommons.org/licen ses/by/4.0/.

\section{References}

Adejumo, A. O. (2010). The need for cultural contextualization in establishing psychological wellness or illness. In I. E. Wells (Ed.), Psychological well-being (pp. 213-222). Nova Science Publishers Inc.

Borja, A. P., Nastasi, B. K., Adelson, E., \& Siddiqui, Z. J. (2016). Cross-cultural patterns of children's phenomenology about stressors and supports. In B. K. Nastasi \& A. P. Borja (Eds.), International handbook of psychological well-being in children and adolescents (pp. 291-309). New York: Springer. https://doi.org/10.1007/978-1-4939-2833-0_17

Bradford, K., Vaughn, L. B., \& Barber, B. K. (2008). When there is conflict: Interparental conflict, parent-child conflict, and youth problem behaviors. Journal of Family Issues, 29(6), 780-805. https:// doi.org/10.1177/0192513x07308043

Bronfenbrenner, U. (1992). Ecological systems theory. Jessica Kingsley Publishers.

Catalano, R. F., Berglund, M. L., Ryan, J. A., Lonczak, H. S., \& Hawkins, J. D. (2004). Positive youth development in the United States: Research findings on evaluations of positive youth development programs. The Annals of the American Academy of Political and Social Science, 591(1), 98-124. https://doi.org/10.1177/0002716203260102

Chen, L. J., Yang, D. L., Zhou, D., \& Ren, Q. (2018). Child and youth well-being in China. Routledge. https://doi.org/10.4324/9780367086145

Chen, M., \& Chan, K. L. (2016). Parental absence, child victimization, and psychological well-being in rural China. Child Abuse \& Neglect, 59, 45-54. https://doi.org/10.1016/j.chiabu.2016.07.009

Chen, X., Wang, L., \& Wang, Z. (2009). Shyness-sensitivity and social, school, and psychological adjustment in rural migrant and urban children in China. Child Development, 80(5), 1499-1513. https:// doi.org/10.1111/j.1467-8624.2009.01347.x 
Chu, P. S., Saucier, D. A., \& Hafner, E. (2010). Meta-analysis of the relationships between social support and well-being in children and adolescents. Journal of Social and Clinical Psychology, 29(6), 624-645. https://doi.org/10.1521/jscp.2010.29.6.624

Deci, E. L., \& Ryan, R. M. (2000). The "what" and "why" of goal pursuits: Human needs and the selfdetermination of behavior. Psychological Inquiry, 11(4), 227-268. https://doi.org/10.1207/s1532 7965pli1104_01

Dohrenwend, B. P., \& Dohrenwend, B. S. (1969). Social status and psychological disorder: A causal inquiry. Wiley.

Evans, G. W., Lepore, S. J., Shejwal, B. R., \& Palsane, M. N. (1998). Chronic residential crowding and children's well-being: An ecological perspective. Child Development, 69(6), 1514-1523. https://doi. org/10.2307/1132129

Fung, A. L. C. (2021). The significance of family structure in internalizing (anxious/depressed) and externalizing (aggressive/delinquent) problems among Chinese adolescents. Applied Research in Quality of Life. https://doi.org/10.1007/s11482-021-09923-9

Garrido, S., Méndez, I., \& Abellán, J. M. (2013). Analysing the simultaneous relationship between life satisfaction and health-related quality of life. Journal of Happiness Studies, 14(6), 1813-1838. https://doi.org/10.1007/s10902-012-9411-X

Hidalgo, J. L. T., Bravo, B. N., Martínez, I. P., Pretel, F. A., Postigo, J. M., \& Rabadán, F. E. (2010). Psychological well-being, assessment tools and related factors. In I. E. Wells (Ed.), Psychological well-being (pp. 77-114). Nova Science Publishers Inc.

Hui, E. K., \& Sun, R. C. (2010). Chinese children's perceived school satisfaction: The role of contextual and intrapersonal factors. Educational Psychology, 30(2), 155-172. https://doi.org/10.1080/01443 410903494452

Jiang, S. (2020). Psychological well-being and distress in adolescents: An investigation into associations with poverty, peer victimization, and self-esteem. Children and Youth Services Review, 111, 104824. https://doi.org/10.1016/j.childyouth.2020.104824

Jones, R., Currow, K., Kwong, M., \& Menon, P. (2016). An innovation in child health: Globally reaching out to child health professionals. Family Medicine and Community Health. https://doi.org/10.15212/ FMCH.2015.0154

Lerner, R. M., Lerner, J. V., Almerigi, J. B., Theokas, C., Phelps, E., Gestsdottir, S., Naudeau, S., Jelicic, H., Alberts, A., Ma, L., Smith, L. M., Bobek, D. L., Richman-Raphael, D., Simpson, I., Christiansen, E. D., \& Eye, A. (2005). Positive youth development, participation in community youth development programs, and community contributions of fifth-grade adolescents: Findings from the first wave of the 4-H study of positive youth development. The Journal of Early Adolescence, 25(1), 17-71. https://doi.org/10.1177/0272431604272461

Leung, C., Leung, J. T., Kwok, S. Y., Hui, A., Lo, H., Tam, H. L., \& Lai, S. (2021). Predictors to happiness in primary students: Positive relationships or academic achievement. Applied Research in Quality of Life. https://doi.org/10.1007/s11482-021-09928-4

Leung, J. T. Y., \& Fung, A. L. (2021). Editorial: Special issue on quality of life among children and adolescents in Chinese societies. Applied Research in Quality of Life. https://doi.org/10.1007/ s11482-021-09915-9

Leung, J. T. Y., \& Shek, D. T. L. (2019). The influence of parental expectations and parental control on adolescent well-being in poor Chinese families. Applied Research in Quality of Life, 14(4), 847865. https://doi.org/10.1007/s11482-017-9540-9

Leung, J. T. Y., \& Shek, D. T. L. (2020). Parental sacrifice, filial piety and adolescent life satisfaction in Chinese families experiencing economic disadvantage. Applied Research in Quality of Life, 15(1), 259-272. https://doi.org/10.1007/s11482-018-9678-0

Li, C., Wu, Q., \& Liang, Z. (2019). Effect of poverty on mental health of children in rural China: The mediating role of social capital. Applied Research in Quality of Life, 14(1), 131-153. https://doi.org/ 10.1007/s11482-017-9584-X

Lim, S. A., You, S., \& Ha, D. (2015). Parental emotional support and adolescent happiness: Mediating roles of self-esteem and emotional intelligence. Applied Research in Quality of Life, 10(4), 631-646. https://doi.org/10.1007/s11482-014-9344-0

Liu, X., \& Zhao, J. (2016). Chinese migrant adolescents' perceived discrimination and psychological well-being: The moderating roles of group identity and the type of school. PLoS ONE, 11(1), e0146559. https://doi.org/10.1371/journal.pone.0146559 
Low, Y. T. A. (2021). Family conflicts, anxiety and depressive symptoms, and suicidal ideation of Chinese adolescents in Hong Kong. Applied Research in Quality of Life. https://doi.org/10.1007/ s11482-021-09925-7

Ma, C. M. S., Shek, D. T. L., \& Chen, J. M. T. (2019). Changes in the participants in a communitybased positive youth development program in Hong Kong: Objective outcome evaluation using a one-group pretest-posttest design. Applied Research in Quality of Life, 14(4), 961-979. https://doi. org/10.1007/s11482-018-9632-1

Ministry of Civil Affairs of the People's Republic of China (2018). Diagram: Data about Chinese rural left-behind children 2018. Retrieved from http://www.mca.gov.cn/article/gk/tjtb/201809/20180 900010882.shtml. Accessed 26 Feb 2021

Pascuzzo, K., Cyr, C., \& Moss, E. (2013). Longitudinal association between adolescent attachment, adult romantic attachment, and emotion regulation strategies. Attachment \& Human Development, 15(1), 83-103. https://doi.org/10.1080/14616734.2013.745713

Pomerantz, E. M., Altermatt, E. R., \& Saxon, J. L. (2002). Making the grade but feeling distressed: Gender differences in academic performance and internal distress. Journal of Educational Psychology, 94(2), 396. https://doi.org/10.1037/0022-0663.94.2.396

Pomerantz, E. M., Saxon, J. L., \& Kenney, G. A. (2001). Self-evaluation: The development of sex differences. In G. B. Moskowitz (Ed.), Cognitive social psychology: On the tenure and future of social cognition (pp. 59-74). Erlbaum. https://doi.org/10.4324/9781410605887-9

Qi, S., Hua, F., Zhou, Z., \& Shek, D. T. L. (2020). Trends of positive youth development publications (1995-2020): A scientometric review. Applied Research in Quality of Life, 1, 1. https://doi.org/10. 1007/s11482-020-09878-3

Roberts, T.-A. (1991). Gender and the influence of evaluations on self-assessments in achievement settings. Psychological Bulletin, 109(2), 297-308. https://doi.org/10.1037/0033-2909.109.2.297

Ryan, R. M., \& Deci, E. L. (2002). An overview of self-determination theory: An organismic-dialectical perspective. In E. L. Deci \& R. M. Ryan (Eds.), Handbook of self-determination research (pp. 3-33). The University of Rochester Press.

Ryff, C. D., \& Singer, B. (1996). Psychological well-being: Meaning, measurement, and implications for psychotherapy research. Psychotherapy and Psychosomatics, 65(1), 14-23. https://doi.org/10.1159/ 000289026

Saleh, M. Y., Shaheen, A. M., Nassar, O. S., \& Arabiat, D. (2019). Predictors of school satisfaction among adolescents in Jordan: A cross-sectional study exploring the role of school-related variables and student demographics. Journal of Multidisciplinary Healthcare, 12, 621-631. https://doi.org/ $10.2147 /$ jmdh.s 204557

Saxbe, D. E., \& Repetti, R. (2010). No place like home: Home tours correlate with daily patterns of mood and cortisol. Personality and Social Psychology Bulletin, 36(1), 71-81. https://doi.org/10.1177/ 0146167209352864

Segrin, C., \& Taylor, M. (2007). Positive interpersonal relationships mediate the association between social skills and psychological well-being. Personality and Individual Differences, 43(4), 637-646. https://doi.org/10.1016/j.paid.2007.01.017

Shek, D. T. L. (1999). Parenting characteristics and adolescent psychological well-being: A longitudinal study in a Chinese context. Genetic, Social, and General Psychology Monographs, 125(1), 27-44.

Shek, D. T. L. (2007). A longitudinal study of perceived parental psychological control and psychological well-being in Chinese adolescents in Hong Kong. Journal of Clinical Psychology, 63(1), 1-22. https://doi.org/10.1002/jclp.20331

Shek, D. T. L. (2008). Economic disadvantage, perceived family life quality, and emotional well-being in Chinese adolescents: A longitudinal study. Social Indicators Research, 85(2), 169-189. https://doi. org/10.1007/s11205-007-9087-5

Shek, D. T. L. (2014). Applied Research in Quality of Life (ARQOL): Where are we and issues for consideration. Applied Research in Quality of Life, 9(3), 465-468. https://doi.org/10.1007/ s11482-014-9340-4

Shek, D. T. L., Dou, D., Zhu, X., \& Chai, W. Y. (2019). Positive youth development: Current perspectives. Adolescent Health, Medicine and Therapeutics, 10, 131-141. https://doi.org/10.2147/AHMT. S179946

Shek, D. T. L., \& Li, X. (2014). Subjective well-being of early adolescents in Hong Kong. In D. T. L. Shek, R. C. Sun, \& C. M. Ma (Eds.), Chinese adolescents in Hong Kong: Family life, psychological well-being and risk behavior (pp. 93-109). Springer. https://doi.org/10.1007/978-981-287-143-5_6 
Shek, D. T. L., \& Liu, T. T. (2014). Life satisfaction in junior secondary school students in Hong Kong: A 3-year longitudinal study. Social Indicators Research, 117(3), 777-794. https://doi.org/10.1007/ s11205-013-0398-4

Shek, D. T. L., \& Ng, C. S. (2014). Family quality of life, personal well-being, and risk behavior in early adolescents in Hong Kong: Related phenomena and research gaps. In D. T. L. Shek, R. C. Sun, \& C. M. Ma (Eds.), Chinese adolescents in Hong Kong: Family life, psychological well-being and risk behavior (pp. 1-18). Singapore: Springer. https://doi.org/10.1007/978-981-287-143-5_1

Shek, D. T. L., \& Siu, A. M. H. (2019). "UNHAPPY” environment for adolescent development in Hong Kong. Journal of Adolescent Health, 64(6), S1-S4. https://doi.org/10.1016/j.jadohealth.2019.01.007

Shek, D. T. L., \& Wu, F. K. (2014). Positive youth development in junior secondary school students: Do gender and time matter? In D. T. L. Shek, R. C. Sun, \& C. M. Ma (Eds.), Chinese adolescents in Hong Kong: Family life, psychological well-being and risk behavior (pp. 35-49). Springer. https:// doi.org/10.1007/978-981-287-143-5_3

Shek, D. T. L., \& Zhu, X. Q. (2020). Promotion of thriving among Hong Kong Chinese adolescents: Evidence from eight-wave data. Research on Social Work Practice, 30(8), 870-883. https://doi.org/10. $1177 / 1049731520947156$

Stallings, M. C., Dunham, C. C., Gatz, M., Baker, L. A., \& Bengtson, V. L. (1997). Relationships among life events and psychological well-being: More evidence for a two-factor theory of well-being. Journal of Applied Gerontology, 16(1), 104-119. https://doi.org/10.1177/073346489701600106

Suldo, S. M., Thalji-Raitano, A., Hasemeyer, M., Gelley, C. D., \& Hoy, B. (2013). Understanding middle school students life satisfaction: Does school climate matter? Applied Research in Quality of Life, 8(2), 169-182. https://doi.org/10.1007/s11482-012-9185-7

Tam, C. C., Li, X., Benotsch, E. G., \& Lin, D. (2020). A resilience-based intervention programme to enhance psychological well-being and protective factors for rural-to-urban migrant children in China. Applied Psychology: Health and Well-Being, 12(1), 53-76. https://doi.org/10.1111/aphw. 12173

To, S., Helwig, C. C., \& Yang, S. (2017). Predictors of children's rights attitudes and psychological wellbeing among rural and urban mainland Chinese adolescents. Social Development, 26(1), 185-203. https://doi.org/10.1111/sode. 12195

Umberson, D., Chen, M. D., House, J. S., Hopkins, K., \& Slaten, E. (1996). The effect of social relationships on psychological well-being: Are men and women really so different? American Sociological Review, 61(5), 837-857. https://doi.org/10.2307/2096456

Van Ryzin, M. J., Gravely, A. A., \& Roseth, C. J. (2009). Autonomy, belongingness, and engagement in school as contributors to adolescent psychological well-being. Journal of Youth and Adolescence, 38(1), 1-12. https://doi.org/10.1007/s10964-007-9257-4

Wang, D., \& Zhou, L. (2017). 2016nian anhuisheng liushou zhongxuesheng xinli xingfugan yu xiaoji xueye qingxu de guanxi ji renzhi chongping de tiaojie zuoyong [Between psychological well-being and negative academic emotions in left-behind middle school student in Anhui Province in 2016: The moderating role of cognitive reappraisal]. Weisheng Yanjiu, 46(6), 935-941.

Warr, P. (2012). How to think about and measure psychological well-being. In R. R. Sinclair, M. Wang, \& L. E. Tetrick (Eds.), Research methods in occupational health psychology (pp. 76-90). Psychology Press/Routledge. https://doi.org/10.4324/9780203095249-16

Wong, F. K. D., Chang, Y. L., \& He, X. S. (2009). Correlates of psychological wellbeing of children of migrant workers in Shanghai, China. Social Psychiatry and Psychiatric Epidemiology, 44(10), 815-824. https://doi.org/10.1007/s00127-009-0003-y

Zhao, Y. H. (2000). Xiaoxue zhi chuzhong jieduan nannv xuesheng chengji chayi yuanyin jiqi kefu tujing [The cause of different marks between boys and girls from primary school to junior middle school and its counter-measures]. Lilun Guancha, 4, 77-80.

Zhu, X., \& Shek, D. T. L. (2020). Impact of a positive youth development program on junior high school students in Mainland China: A pioneer study. Children and Youth Services Review, 114, 105022. https://doi.org/10.1016/j.childyouth.2020.105022

Publisher's Note Springer Nature remains neutral with regard to jurisdictional claims in published maps and institutional affiliations. 